\title{
Reducing Maintenance and Rehabilitation Costs through the Use of AMIR Compaction
}

\author{
O. Abd El Halim ${ }^{1, *}$, F. Pinder ${ }^{2}$, A. Rajendran Chelliah ${ }^{1}$, O. Abdelalim ${ }^{1}$ \\ ${ }^{1}$ Department of Civil and Environmental Engineering, Carleton University, Ottawa, K1S 5B6, Ontario, Canada \\ ${ }^{2}$ Head Quality Assurance, Ministry of Transportation, Kingston, Ontario, Canada \\ *Corresponding Author: a_halim@carleton.ca
}

Copyright (C) 2013 Horizon Research Publishing All rights reserved.

\begin{abstract}
Highway engineers and administrators, and Construction industry made necessary improvements to asphalt pavements in the field of asphalt binders to bond asphalt layers, material selection, testing procedure, mix design method, material handling and through significant technological advancement in laying process. These actions and efforts created an assumption that newly constructed asphalt pavements which meet design objectives are structurally sound. However no significant improvements to the current compaction equipment and techniques were made to date. Pavement surface cracks which are induced by current compaction method ruins the above combined effort made by authorities and industry to achieve long lasting pavement. Improving compaction practice by introducing a new compactor; AMIR, can provide the quality of highway network with respect to authorities and industry expectation. This paper as well as earlier studies shows that AMIR roller applies low compaction pressure over a long contact duration which helps to provide efficient particle contact, expulsion of entrained air and keeps the initial stiffness response of the asphalt at low. Large contact area of the roller minimizes horizontal forces applied to the asphalt mat and provides a high degree of confinement during compaction. Elimination of roller induced cracking reduces surface permeability, increases density with less passes, improves resistance to fatigue damage and permits the full compaction energy to be applied to the pavement layer. This will enhance the existing necessary improvements made by transportation authorities in highway construction. Also, the end product is expected to reduce the required maintenance and rehabilitation costs which have been performed more frequent than expected.
\end{abstract}

Keywords Asphalt Binder, Compaction, Compaction Pressure, Contact Area, Density, Fatigue Damage, Permeability, Surface Crack

\section{Introduction}

Asphalt pavement makes up 95\% of Ontario road network
[1]. The excepted service life of most asphalt pavements that are designed and built in Ontario are in the range of 15 to 20 years [2]. However, this design objective is rarely met because of the uncertainty of many design and construction variables that leads to early failures and premature deteriorated surfaces. Several major research initiatives in the field of asphalt binders to bond asphalt layers, material selection and handling, testing procedure, mix design method were launched by Ministry of Transportation Ontario (Highway infrastructure innovation funding program). These attempts are carried out in order to find effective and reliable solutions to address old problems that are still unsolved today such as reflection cracking, rutting, stripping and other similar pavement problems.

The solutions provided by Hot Mix Asphalt pavement (HMA) Community for pavement problems until now are mainly materials based. The main course of action remained, modification to asphalt mix design as well as selection of different materials. Majority of predicted solutions deals in part with the characterization of asphalt materials and their performance under a wide range of in-service conditions, and the adoption of gyratory compaction as the main laboratory device for designing asphalt mixes. Also the use of advanced materials such as polymer modified asphalt binders with improved tensile and shear strengths to reinforce asphalt layers, the introduction of end-result specifications and performance based specifications [3] have contributed to an improvement in pavement performance. These and other initiatives have a significant impact on the performance of asphalt pavements both in the short and long term. However, in spite of these efforts long term performance of pavement has not been successfully achieved. A key important factor remain unaddressed which as a potential to affect performance of asphalt pavement is asphalt compaction.

Compaction has been recognized by HMA community as one of the most important factors affecting performance and the least expensive element in extending the service life of asphalt pavement. Unfortunately, no significant improvement had been made to compaction equipment since asphalt roads were using rollers for construction. This is 
despite the fact that rollers have a greater importance with Superpave designs because of the higher aggregate content, increased asphalt sticking /stiffness of the mat, and the need to measure both density and temperature during compaction. HMA community still in the assumption that base stability, operator error, temperature during compaction and/ or the asphalt mix itself attributes to compaction problems such as construction cracks also known as "checking". Moreover, construction cracks are still assumed to be "probably more unsightly than physically detrimental"[4], or to be corrected with pneumatic-rubber tired rollers. It has been conclusively proven that construction cracks are caused by conventional steel drum rollers and that such cracks are detrimental to the long-term pavement performance by reducing fatigue life by more than 50 percent [5-7]. This research work further concluded that pneumatic-rubber tired rollers do not eliminate the cracks. This is further illustrated by the fact that as more and more Superpave mixtures go to the field, compaction problems are occurring [8]. The overall purpose of this paper is to present an overview of the crack initiation due to the traditional compaction practices, the effect of construction cracks on pavement performance. The paper also highlights the success of the new AMIR compaction technology in improving the compaction process of asphalt concrete pavements.

\section{Materials and Methods}

\subsection{Cracking in Asphalt Concrete Surfaces}

"Reflective cracking" is the most observed cracking in asphalt pavements which includes fatigue and thermal cracking. Fatigue cracking is attributed to repeated loading due to traffic. Himeno and Watnabe [9] study states "Fatigue failure can initiate at the top of the mix slab, when the mix stiffness modulus is low." Low stiffness could result in poor compaction and inadequate methods of compaction.

Low temperature cracking in asphalt is generally induced by a drop in the temperature. Basic mechanism of low temperature cracking has been investigated by Christison [10]. Under decreasing temperature, a micro-crack may develop at the pavement surface and then propagate through the full depth of the asphalt layer with successive thermal cycles. The full development of these cracks can be significantly accelerated due other reasons, such as compaction.

Reflective cracking have been traditionally thought to develop at the bottom of the asphalt concrete mat at the same location of the previously existing cracks in the under layers and then these cracks propagate to the surface. However, research work carried out by Abd El Halim et.al [11,12] has shown that this type of cracking is initiated during compaction at the surface and then propagates to the bottom of the mat near the existing old cracks. Based on the previous discussion, it can be concluded that the life of the asphalt concrete mat is significantly affected by the presence of surface cracking. It should be noted that surface cracks is not the only reason for the development of the different types of cracking in asphalt pavements, but it can also serve as a contributor to accelerate the development of cracking and ultimately reduce pavements service life.

\subsection{Mechanics of Asphalt Compaction}

In a comprehensive study in 2004 [13], it was concluded that "in practice the compaction process is the key element in establishing the final quality of the road. Compaction of asphalt is mainly based on experimental knowledge. From experiences with compaction of asphalt mixes gained in the past, one can estimate what results to expect when comparable mixtures are compacted under similar circumstances. If we operate outside the experience domain the results of compaction are uncertain. At present this is often the case since regularly roads are maintained under adverse conditions and new types of mixtures are being used."

Clearly, this observation suggested that compaction of asphalt mixtures depended very much on experience and less on scientific understanding of the process itself. The work presented in this paper differs from the conclusion reported in the 2004 study since the AMIR compaction technique has been developed based on sound theoretical and experimental basis. Therefore, the mechanical and physical properties of compacted asphalt mixtures can be improved without relying on the uncertainty associated with the present approach.

The mechanics of compaction involves three factors: compressive force of the roller, the force within the mix that resists the force of the roller, and the supporting forces provided by the stable surface beneath the asphalt concrete mat.

Compaction of an asphalt material by roller involves four forces: static load, manipulation, impact and vibration. Impact and vibration are dynamic and generate higher compaction forces, while on other hand static and manipulation are static generate lower compaction forces. For compaction to occur, the static force of the roller comes from both the weight of the roller (steel roller), wheel load and tire pressure (Pneumatic roller). Manipulation force from pneumatic roller is generated when lines of force are not vertical. Weight of roller produces Impact force. Weight of the roller produce impact force, vibratory force is produced by vibratory asphalt compactor which increases the compactive effort developed by weight and impact.

The supporting forces in the subgrade result from the subgrade stability. Firmness and resisting forces are the result of the inter-particle friction between the aggregate particles, in addition to the viscosity of the asphalt binder. When the mix density and the temperature reach a point where the resisting force equal the compressive force of the rollers and the resistant forces of the subgrade, equilibrium is reached and the compaction process is complete. This requires displacing the aggregate particles in relation to each other to achieve minimal voids, in addition to decreasing the 
volume air, moisture, and bitumen vapour in the mix. Decreasing vapour volume can be achieved through cooling the vapour, thus decreasing its volume and increasing the pressure through rolling

\subsection{Current Practices}

Current HMA community compaction method is carried out with three different types of compactors. The construction of asphalt pavements is carried out by placing the hot mix asphalt over a base course or an existing road surface, and the first operation in the compaction procedure uses a heavy vibratory steel roller that induces greater compactive effort to obtain the desired density. Greater compactive effort is necessary, as Superpave design method results in higher required density at lower asphalt content with a higher aggregate percentage and aggregate contact compared to traditional mixes. Another reason for the greater compactive effort is to achieve higher density soon after the initial lay down because some binders are much stiffer at a higher temperature. Smoothing out the surface is accomplished with a multi wheeled rubber roller followed by a light steel roller. The finished product is assumed to be structurally sound and free of defects. Due to the mismatch of the geometry and relative rigidities between the more rigid, cylindrical compacted device and the softer and flat hot asphalt mat, existing rollers provide finished asphalt layers with the following flaws:

1. Surface cracks (roller checking) or damaged stones,

2. Non-uniform densities along and across the compacted mat,

3. Poor bond between the top asphalt layer and the underlying layers,

4. Damaged edges, especially when unsupported, and

5. Poor longitudinal joints.

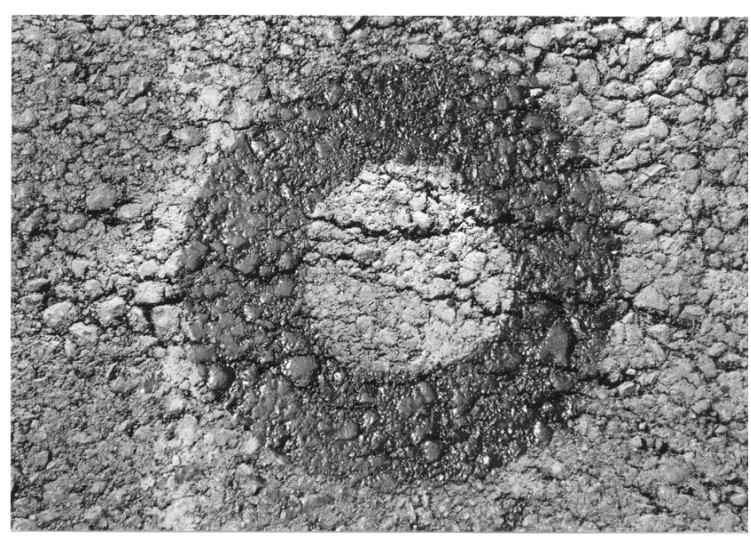

Figure 1. Compacted surface using steel and pneumatic rollers

In addition to these problems, current compaction techniques require the use of more than one type of roller, highly trained workers, and costly maintenance. Furthermore, the use of vibrating rollers to compact thin lifts of asphalt mats can seriously damage the new layer during compaction. These problems have been well documented by Abd El Halim
$[11,12,14]$. They have also led to the development of a new compaction technology, which overcomes the engineering limitations associated with present rollers, as subsequently described. Figure 1 shows the cracks in HMA layer compacted using steel and pneumatic rollers.

\subsection{Crack Development}

The presence of greater compactive effort on a Superpave mix that has higher percentage of aggregate which are fully crushed results in greater potential to cause aggregate damage. Research work carried out by Abd El Halim et.al [15] emphasized two major negative effects concerning asphalt compaction.

First, point loads applied rapidly for a short duration cause the asphalt to respond with a high elastic stiffness and relatively small plastic deformation. To overcome the increased asphalt stiffness, conventional equipment seeks to increase the applied load or to use vibration, which may cause breakage of the aggregate particles. Second, the small contact area causes the application of horizontal (shoving) forces to the asphalt layer. As the roller travels, the horizontal forces push and pull the asphalt in front of and behind the drum, respectively, causing surface cracking with an interrelated dissipation of a significant portion of the applied compaction energy as shown in Figure 2. The induction of surface cracking at this stage of construction reduces the strength and fatigue resistance of the asphalt layer, and facilitates the development of cracking, which can ultimately cause the premature failure of the pavement (still in the review stage by HMA community)

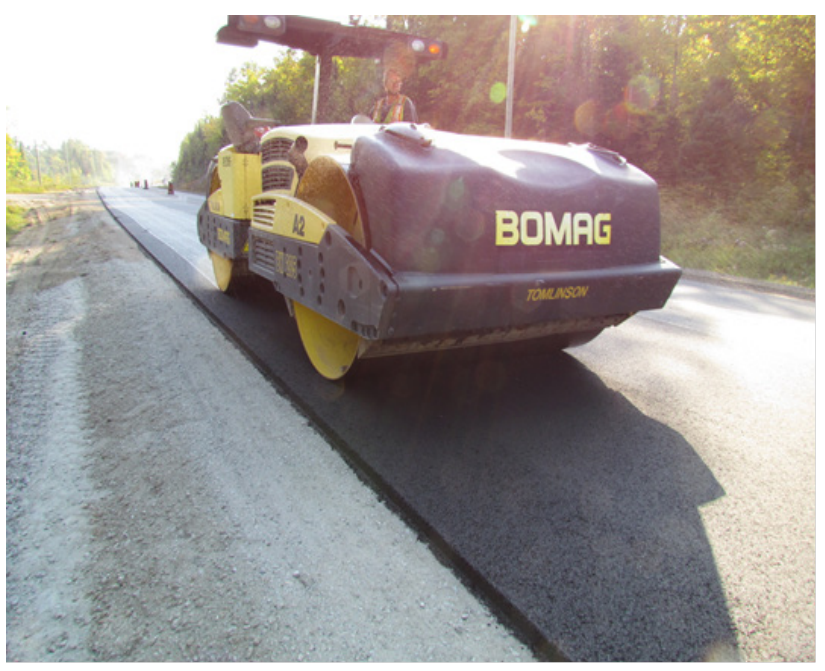

Figure 2. Compaction by Steel Roller

Although the presence of surface cracks developed during construction is not the only reason for the development of the different types of cracking in asphalt pavements, these surface cracks serve as catalysts, which accelerate the development of cracking and ultimately the failure of the pavements. Furthermore, the early presence of the 
construction induced cracks in the surface of the new asphalt layer allow water to infiltrate into the asphalt pavement structure causing stripping and damage of its strength.

\subsection{Asphalt Multi-Integrated Roller Technology}

Roller cracking has been attributed to the incompatibility between the geometry and relative rigidity of the soft, flat asphalt layer and the hard, cylindrical steel drums of conventional rollers [11]. To overcome these incompatibilities, AMIR uses a multi-layered belt to create a single flat contact area for compaction. The rubber belt is flexible, providing a closer match in rigidity to the asphalt surface. The initial stiffness response of the asphalt is kept low by the low compaction pressure applied gradually over a long duration. The long load duration also compensates for the low applied pressure by allowing visco-plastic flow of the asphalt, providing efficient particle contact and expulsion of entrained air. Furthermore, the large contact area minimizes the horizontal forces applied to the asphalt mat and provides a high degree of confinement during compaction. This, in turn, eliminates the roller induced cracking, reduces surface permeability, and increases tensile strength and resistance to fatigue damage. The elimination of surface cracking also permits the full compaction energy to be applied to the pavement layer. For further information about the AMIR prototype, is well described in the literature [5]. The early AMIR I prototype was modified to improve its steering abilities and maneuverability by designing an additional unit to provide these characteristics. Figure 3 illustrates the modified AMIR II with its steering unit. The new upgraded AMIR II was used to perform several field trials on a number of Ontario highway projects and a number of in-house test sections in the city of Ottawa during the summer of 2012.

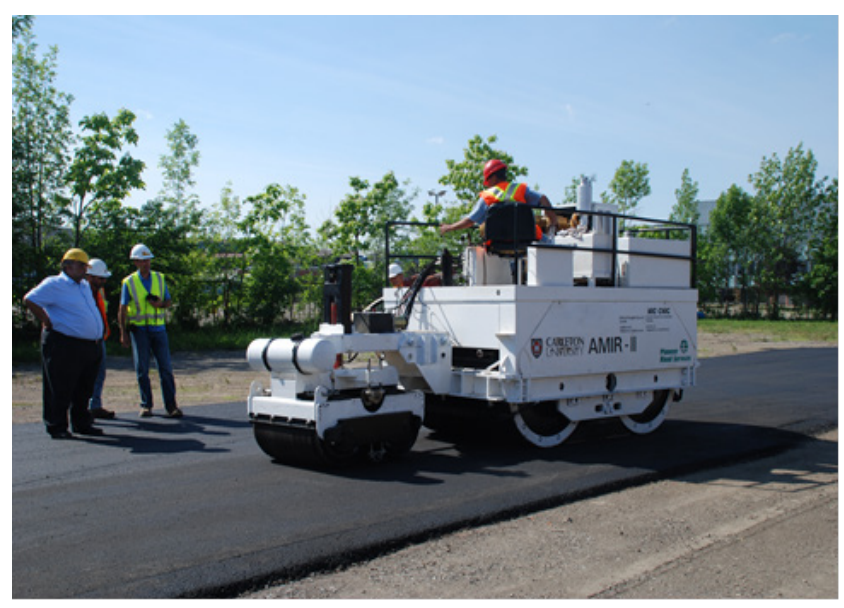

Figure 3. Compaction by AMIR II

\subsection{Review of Amir Field Trial Results}

\subsubsection{Earlier Field Tests}

AMIR I prototype was used in several field trials in
Canada, Sweden during 1989-2006 and in Australia (AMIR I and the improved HIPAC) during 1997-2002. Detailed compaction and performance results observed with AMIR in Canada and Australia compared to conventional compaction equipment are found in numerous papers, including Abd El Halim et al [5] and Richards et al [16]. However, it is useful to present a brief review of the major conclusions of these field trials so that it can be compared with the present study.

Earlier studies found that the AMIR compacted sections showed a crack-free surface with tighter texture. Permeability tests computed in Canada and Australia indicated that the sections compacted using conventional equipment were between 2 to 10 times more permeable than the compacted sections of AMIR. Furthermore, AMIR achieved higher specific gravities and better uniformity of the density distribution than those achieved by the static steel roller. In addition AMIR compacted pavements gave better mechanical performance in terms of fatigue lives, indirect tensile strength and stripping resistance when compared with conventionally compacted mixes

Table 1. Comparison of Field Test Findings

\begin{tabular}{|l|l|}
\hline AMIR & Current HMA rolling method \\
\hline $\begin{array}{l}\text { Provided } 3 \text { times less permeable } \\
\text { layer than current HMA } \\
\text { compaction practice }\end{array}$ & $\begin{array}{l}\text { Provided 3 times more permeable } \\
\text { layer than AMIR }\end{array}$ \\
\hline $\begin{array}{l}\text { Single roller performed all the } \\
\text { compaction needs }\end{array}$ & $\begin{array}{l}\text { Combination of 3 roller used for } \\
\text { compaction }\end{array}$ \\
\hline $\begin{array}{l}\text { Compaction was achieved } \\
\text { without using vibration }\end{array}$ & $\begin{array}{l}\text { Vibratory roller was used to } \\
\text { achieve required compaction }\end{array}$ \\
\hline $\begin{array}{l}\text { Less number of passes required } \\
\text { to achieve the required field } \\
\text { density }\end{array}$ & $\begin{array}{l}\text { Required 5-8 more passes than } \\
\text { AMIR to achieve the required } \\
\text { field density }\end{array}$ \\
\hline $\begin{array}{l}\text { Environmental friendly (less } \\
\text { carbon emission) }\end{array}$ & $\begin{array}{l}2 \text { times more carbon emission } \\
\text { compared to AMIR }\end{array}$ \\
\hline $\begin{array}{l}\text { Economical ( Saves Manpower, } \\
\text { fuel and time compare to current } \\
\text { HMA compaction practice ) }\end{array}$ & Uneconomical compare to AMIR \\
\hline $\begin{array}{l}\text { Achieved tighter and smoother } \\
\text { finished surface }\end{array}$ & $\begin{array}{l}\text { Less tighter and smoother } \\
\text { finished surface compared to } \\
\text { AMIR }\end{array}$ \\
\hline Achieved required density & Achieved required density \\
\hline $\begin{array}{l}\text { Does not require highly trained } \\
\text { operators }\end{array}$ & $\begin{array}{l}\text { Does not require highly trained } \\
\text { operators }\end{array}$ \\
\hline
\end{tabular}

\subsubsection{Amir II Field Tests}

In 2012, due to new interest in the AMIR compaction technology, an improved modified AMIR II prototype with its old belt was used to compact field test sections of Ontario highways in the regions of Barry's Bay and 1000 Island Parkway. In addition, other field test section at HWY 28 and in-house trails in Power Rd Tomlinson yard were completed using a new rubber belt as the old belt was decrepit. Improvements in Steering control, tension mechanism, new belt and battery transformed AMIR I into improved modified 
AMIR II. A brief summary of comparison of field test findings and results obtained from the field trials in HWY 28 and the in-situ test section in the City of Ottawa are given in Table 1.

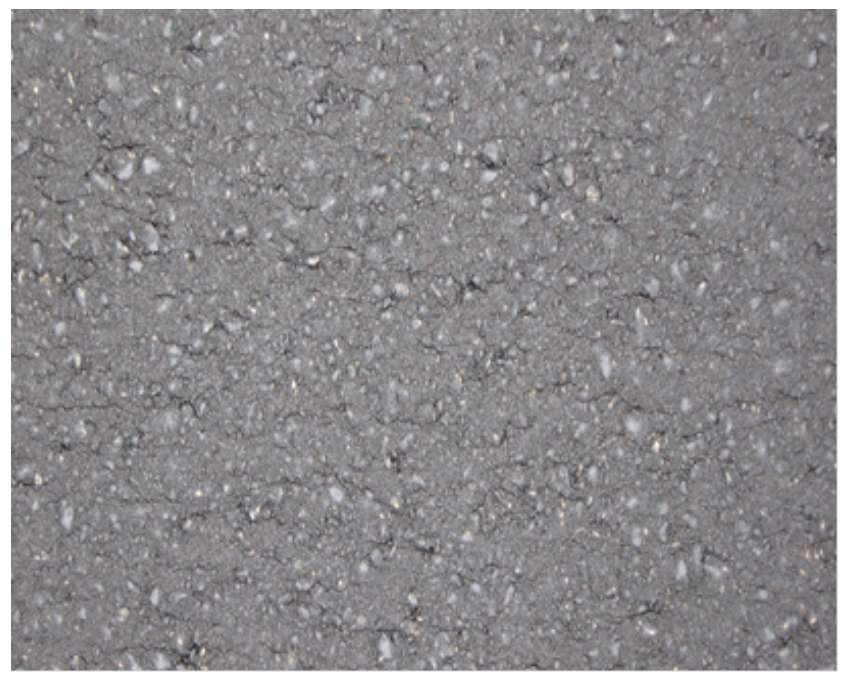

Figure 4. Steel Roller Compacted Surface

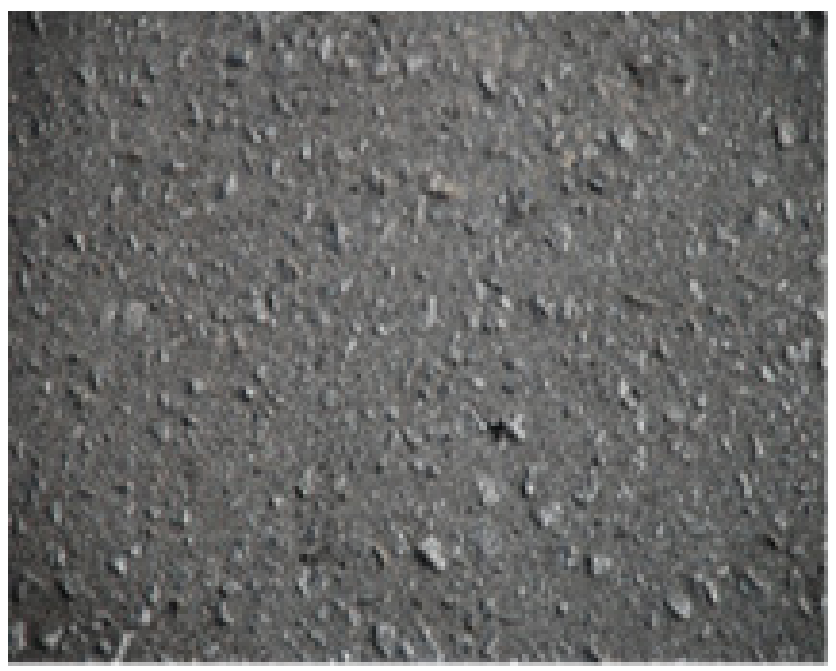

Figure 5. AMIR II compacted Surface

\subsection{General Observations}

Several important observations were reported during and after the compaction of the field sections. First, it was observed that construction cracks are initiated during the application of the steel roller as shown in Figure 4. The use of the rubber pneumatic roller did not remove those cracks and they remained visible after completion of the compaction process which confirmed observations reported before by Abd El Halim et.al [12]. When AMIR II compactor was used no cracking was observed and a much tighter texture was the results as shown in Figure 5. When field permeability measurements were taken, water was noted to have penetrated the asphalt layer under the ring of the test facility and appears back on the surface outside the ring. This observation was not reported on the AMIR compacted section. This observation is important since it explains how potholes can form. Clearly, water would infiltrates the surface through the construction induced cracks and remain closer to the surface. Under cold temperatures the water freezes and expands in volume forcing its way through the surface cracks and widening them. As the temperature warm up and frozen water starts to melt traffic loads would operate as a pump, forcing the trapped water to move in all directions within the asphalt layer until potholes are formed

\subsubsection{Results of Highway 28}

Highway 28 is a Provincial Highway, which runs southwest-northeast from Highway 7 east of Peterborough, to Highway 41 in Denbigh, Ontario, Canada. The field test section was a part of 2012 MTO paving projects near the town of Bancroft. The field test section consists of 500 meter long by 4.25 -meter width and $50 \mathrm{~mm}$ thickness. The test sections were compacted using AMIR II as shown in Figure 3 on one section while the other section was completed using conventional compaction methods utilizing the three typical rollers of steel vibratory, pneumatic rubber and static steel compactors. After the compaction was completed, field tests were performed to measure the permeability and smoothness of the finished surfaces while cores samples were recovered from each test section for laboratory determination of compaction, density and tensile strength values. The results are given in Tables 2 to 5 . As shown in the tables, AMIR compaction provides overall better densities, comparable indirect tensile strength in addition to much tighter surface texture as supported by the lower values of measured permeability. Figure 5 shows AMIR II crack free surface while Figure 6 demonstrates the in-situ permeability test.

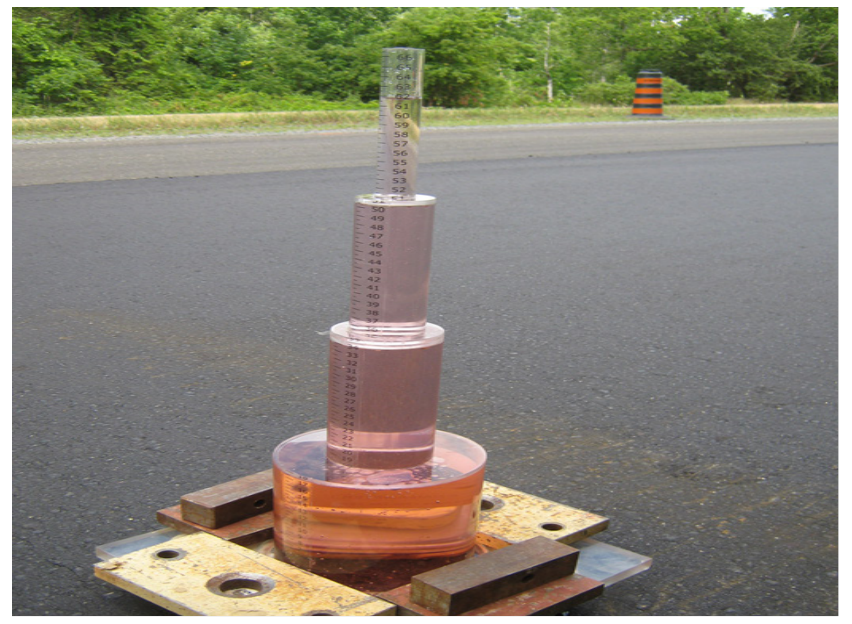

Figure 6. AMIRII Surface Permeability

Before using the modified AMIR II on the highways sections, it was successfully evaluated for steering abilities and climbing up and down typical steep road sections Figure 7. 


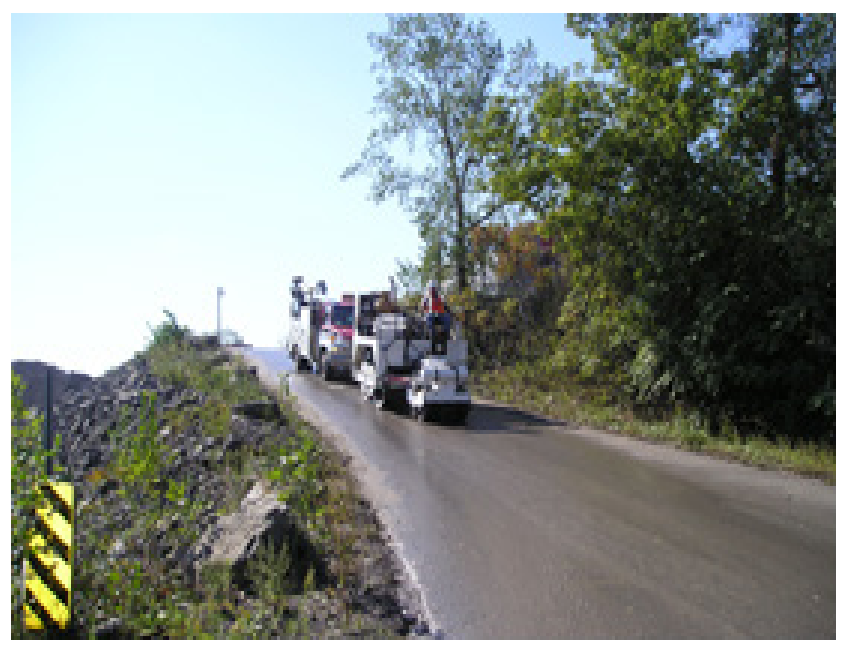

Figure 7. AMIR II steering abilities

\subsection{In-situ Tomlinson Yard Ottawa Test Section}

In- house asphalt layer was HL-3 provided by Tomlinson groups Ltd from their Rideau Plant in Ottawa. This section consisted of 60 meter long by 9-meter width and $50 \mathrm{~mm}$ thickness and was compacted using AMIR II side by side with the conventional steel roller. After the compaction, permeability tests were performed and the results are given in Tables 6 to 9. As shown in the Table, the AMIR compaction provides much tighter surface which is confirmed by the measured $\mathrm{K}$ values and an average ratio of steel to AMIR of 5.6 and achieved tensile strength and higher density by 4 passes lesser than Vibratory steel roller.

Current HMA community compaction method is carried out with three different types of compactors. The construction of asphalt pavements is carried out by placing the hot mix asphalt over a base course or an existing road surface, and the first operation in the compaction procedure uses a heavy vibratory steel roller that induces greater compactive effort to obtain the desired density. Greater compactive effort is necessary, as Superpave design method results in higher required density at lower asphalt content with a higher aggregate percentage and aggregate contact compared to traditional mixes. Another reason for the greater compactive effort is to achieve higher density soon after the initial lay down because some binders are much stiffer at a higher temperature. Smoothing out the surface is accomplished with a multi wheeled rubber roller followed by a light steel roller. The finished product is assumed to be structurally sound and free of defects.

Table 2. Permeability Test Results HWY 28, 2012

\begin{tabular}{|c|c|c|c|c|c|}
\hline TYPE & Initial reading & Final reading & Time (sec) & $\mathrm{k}$ & Average $\quad(\mathrm{cm} / \mathrm{sec})$ \\
\hline \multirow{14}{*}{$\begin{array}{l}\text { Current HMA } \\
\text { Rolling Pattern }\end{array}$} & 49 & 37 & 39.38 & $5.600 \mathrm{E}-03$ & \multirow{14}{*}{$3.40 \mathrm{E}-03$} \\
\hline & 33 & 27 & 60.7 & $6.409 \mathrm{E}-03$ & \\
\hline & 62 & 52 & 21.64 & $1.172 \mathrm{E}-03$ & \\
\hline & 49 & 45 & 68.99 & $9.691 \mathrm{E}-04$ & \\
\hline & 49 & 37 & 39.95 & $5.276 \mathrm{E}-03$ & \\
\hline & 32 & 27 & 64.04 & $4.915 \mathrm{E}-03$ & \\
\hline & 49 & 39 & 54.59 & $3.138 \mathrm{E}-03$ & \\
\hline & 49 & 37 & 120.02 & $1.756 \mathrm{E}-03$ & \\
\hline & 45 & 36 & 22.38 & $7.482 \mathrm{E}-03$ & \\
\hline & 33 & 27 & 52.67 & $7.059 \mathrm{E}-03$ & \\
\hline & 63 & 52 & 25.32 & $1.044 \mathrm{E}-03$ & \\
\hline & 49 & 43 & 109.13 & $8.982 \mathrm{E}-04$ & \\
\hline & 63 & 52 & 60.06 & $4.403 \mathrm{E}-04$ & \\
\hline & 62 & 53 & 15.34 & $1.409 \mathrm{E}-03$ & \\
\hline \multirow{14}{*}{ AMIR II } & 64 & 53 & 105.88 & $2.500 \mathrm{E}-04$ & \multirow{14}{*}{$1.11 \mathrm{E}-03$} \\
\hline & 63 & 53 & 45.19 & $5.661 \mathrm{E}-04$ & \\
\hline & 64 & 54 & 34.72 & $7.242 \mathrm{E}-04$ & \\
\hline & 50 & 47 & 46.96 & $1.062 \mathrm{E}-03$ & \\
\hline & 58 & 52 & 7.58 & $2.132 \mathrm{E}-03$ & \\
\hline & 49 & 45 & 26.5 & $2.590 \mathrm{E}-03$ & \\
\hline & 61 & 52 & 19.42 & $1.154 \mathrm{E}-03$ & \\
\hline & 49 & 44 & 86.59 & $9.500 \mathrm{E}-04$ & \\
\hline & 49 & 38 & 52.9 & $3.773 \mathrm{E}-03$ & \\
\hline & 63 & 53 & 30.14 & $8.048 \mathrm{E}-04$ & \\
\hline & 50 & 46 & 83.42 & $7.639 \mathrm{E}-04$ & \\
\hline & 63 & 58 & 71.91 & $1.658 \mathrm{E}-04$ & \\
\hline & 64 & 58 & 167.58 & $8.244 \mathrm{E}-05$ & \\
\hline & 49 & 37 & 68.73 & $5.632 \mathrm{E}-04$ & \\
\hline
\end{tabular}

Mean $\mathrm{K}$ value for AMIR $=1.11-3$

Mean $\mathrm{K}$ value for current HMA rolling pattern $=3.40-3$

Ratio of the $\mathrm{K}$ values of current HMA rolling pattern and $\mathrm{AMIR}=3.1$ 
Table 3. BRD and Tensile strength (direction of rolling)

\begin{tabular}{|c|c|c|c|}
\hline \multicolumn{2}{|c|}{ BRD } & \multicolumn{2}{c|}{$\begin{array}{c}\text { Tensile strength } \\
\text { (direction of rolling) KN/m2 }\end{array}$} \\
\hline AMIR & current HMA rolling pattern & AMIR & current HMA rolling pattern \\
\hline 2.348 & 2.311 & 137.88 & 70.77 \\
\hline 2.318 & 2.341 & 76.87 & 117.40 \\
\hline 2.401 & 2.332 & 99.66 & 115 \\
\hline 2.345 & 2.341 & 100.17 & 83.94 \\
\hline 2.357 & 2.308 & 75.76 & $(96.87$ \\
\hline$(2.354) 1$ & $(2.327) 1$ & $(98.07) 1$ & \\
\hline
\end{tabular}

1: mean values

Table 4. BRD and Tensile strength (Perpendicular to rolling direction)

\begin{tabular}{|c|c|c|c|}
\hline \multicolumn{2}{|c|}{ BRD } & \multicolumn{2}{c|}{$\begin{array}{c}\text { Tensile strength } \\
\text { (perpendicular to rolling) KN/m2 }\end{array}$} \\
\hline AMIR & current HMA rolling pattern & AMIR & current HMA rolling pattern \\
\hline 2.354 & 2.325 & 100.31 & 111.75 \\
\hline 2.305 & 2.305 & 99.74 & 112.49 \\
\hline 2.217 & 2.237 & 79.69 & 72.99 \\
\hline 2.358 & 2.279 & 112.88 & 90.02 \\
\hline 2.364 & 2.320 & 95.39 & 106.31 \\
\hline$(2.320)$ & $(2.293)$ & $(97.67)$ & $(98.71)$ \\
\hline
\end{tabular}

Mean AMIR BRD $=2.337$

Mean Current HMA Rolling Pattern $=2.310$

Mean AMIR Tensile strength $=97.83$

Mean Current HMA Rolling Pattern tensile strength $=97.47$

Table 5. ASPHALT -IRI SMOOTHNESS using AMES Engineering Profiler

\begin{tabular}{|c|c|c|c|c|c|c|c|c|c|c|c|c|c|c|c|c|}
\hline \multirow{2}{*}{\multicolumn{5}{|c|}{ LOCATION: hwy 28}} & \multicolumn{12}{|c|}{ SURFACE SMOOTHNESS MEASUREMENTS - IRI (M/KM) } \\
\hline & & & & & \multicolumn{3}{|c|}{ RUN 1} & \multicolumn{3}{|c|}{ Run 2} & \multicolumn{3}{|c|}{ RUN 3} & \multicolumn{3}{|c|}{ AVERAGE } \\
\hline $\begin{array}{l}\text { Subl } \\
\text { ot \# }\end{array}$ & $\begin{array}{l}\text { High } \\
\text { way } \\
\text { Dire } \\
\text { ction }\end{array}$ & $\begin{array}{c}\text { Starti } \\
\text { ng } \\
\text { Chai } \\
\text { nage }\end{array}$ & $\begin{array}{c}\text { Endi } \\
\text { ng } \\
\text { Chai } \\
\text { nage }\end{array}$ & $\begin{array}{l}\text { Leng } \\
\text { th }\end{array}$ & Left & Right & $\begin{array}{l}\text { Aver } \\
\text { age }\end{array}$ & Left & $\begin{array}{c}\text { Righ } \\
\mathrm{t}\end{array}$ & $\begin{array}{c}\text { Aver } \\
\text { age }\end{array}$ & Left & $\begin{array}{c}\text { Righ } \\
\mathrm{t}\end{array}$ & $\begin{array}{l}\text { Aver } \\
\text { age }\end{array}$ & Left & $\begin{array}{c}\text { Righ } \\
\mathrm{t}\end{array}$ & $\begin{array}{l}\text { Aver } \\
\text { age }\end{array}$ \\
\hline \multicolumn{17}{|c|}{$\begin{array}{l}\text { AMIR TEST SECTION }(12+875 \text { TO } \\
13+390)\end{array}$} \\
\hline 30 & NB & $\begin{array}{c}12+8 \\
55\end{array}$ & $\begin{array}{c}13+0 \\
00\end{array}$ & 115 & .660 & .660 & .660 & .660 & .680 & .670 & .660 & .650 & .655 & .660 & .663 & .662 \\
\hline 31 & NB & $\begin{array}{c}13+0 \\
00\end{array}$ & $\begin{array}{c}13+1 \\
40\end{array}$ & 140 & .960 & .900 & .930 & .950 & .870 & .910 & .900 & .920 & .910 & .937 & .897 & .917 \\
\hline & & & & & & & & & & & & & \multicolumn{3}{|c|}{ Average NB } & 0.79 \\
\hline 32 & NB & $\begin{array}{c}13+1 \\
60\end{array}$ & $\begin{array}{c}13+3 \\
00\end{array}$ & 140 & .900 & .870 & .885 & .880 & .890 & .885 & .890 & .87 & .880 & .890 & .877 & .883 \\
\hline 33 & NB & $\begin{array}{c}13+3 \\
00\end{array}$ & $\begin{array}{c}13+3 \\
90\end{array}$ & 90 & .870 & .850 & .860 & .860 & .850 & .855 & .850 & .850 & .850 & .860 & .850 & .855 \\
\hline & & & & & & & & & & & & & \multicolumn{3}{|c|}{ Average NB } & .870 \\
\hline \multicolumn{17}{|c|}{$\begin{array}{l}\text { Conventional CONTROL SECTION } \\
(12+875 \text { to } 13+390)\end{array}$} \\
\hline 244 & SB & $\begin{array}{c}13+3 \\
90\end{array}$ & $\begin{array}{c}13+3 \\
00\end{array}$ & 90 & .850 & .560 & .705 & .880 & .550 & .715 & .930 & .550 & .740 & .887 & .553 & .720 \\
\hline 245 & SB & $\begin{array}{c}13+3 \\
00\end{array}$ & $\begin{array}{c}13+1 \\
60\end{array}$ & 140 & .640 & .630 & .635 & .630 & .630 & .630 & .650 & .630 & .640 & .640 & .630 & .635 \\
\hline & & & & & & & & & & & & & \multicolumn{3}{|c|}{ Average SB } & .680 \\
\hline 246 & SB & $\begin{array}{c}13+1 \\
40\end{array}$ & $\begin{array}{c}13+0 \\
00\end{array}$ & 140 & .840 & .980 & .910 & .840 & .980 & .910 & 0.86 & .98 & .92 & .847 & .980 & .913 \\
\hline 247 & SB & $\begin{array}{c}13+0 \\
00\end{array}$ & $\begin{array}{c}12+8 \\
85\end{array}$ & 115 & .640 & .710 & .675 & .650 & .730 & .690 & .670 & .690 & .680 & .653 & .710 & .682 \\
\hline & & & & & & & & & & & & & \multicolumn{3}{|c|}{ Average SB } & .800 \\
\hline
\end{tabular}


Table 6. Permeability Test Results Tomlinson Power Rd Yard, 2012

\begin{tabular}{|c|c|c|c|c|c|}
\hline TYPE & Initial Height & Initial Height & Time (sec) & $\mathrm{k}$ & Average $\quad(\mathrm{cm} / \mathrm{sec})$ \\
\hline \multirow{7}{*}{$\begin{array}{l}\text { Vibratory } \\
\text { Steel roller }\end{array}$} & 63 & 52 & 6.4 & $3.634 \mathrm{E}-03$ & \multirow{7}{*}{ 2.02E-03 } \\
\hline & 63 & 52 & 22.3 & $1.043 \mathrm{E}-03$ & \\
\hline & 63 & 53 & 18 & $1.127 \mathrm{E}-03$ & \\
\hline & 66 & 53 & 188.5 & $1.411 \mathrm{E}-04$ & \\
\hline & 49 & 36 & 43 & $4.583 \mathrm{E}-03$ & \\
\hline & 63 & 53 & 6.8 & $2.984 \mathrm{E}-03$ & \\
\hline & 63 & 53 & 33.8 & $6.003 \mathrm{E}-04$ & \\
\hline \multirow{7}{*}{ AMIR II } & 63 & 52 & 55.7 & $3.516 \mathrm{E}-04$ & \multirow{7}{*}{$1.98 \mathrm{E}-04$} \\
\hline & 62 & 52 & 97.5 & $1.841 \mathrm{E}-04$ & \\
\hline & 63 & 58 & 67.9 & $1.243 \mathrm{E}-04$ & \\
\hline & 63 & 53 & 63.7 & $3.150 \mathrm{E}-04$ & \\
\hline & 63 & 55 & 111.4 & $1.415 \mathrm{E}-04$ & \\
\hline & 63 & 60 & 100.2 & $5.654 \mathrm{E}-05$ & \\
\hline & 63 & 53 & 95.1 & $2.110 \mathrm{E}-04$ & \\
\hline
\end{tabular}

Mean $\mathrm{K}$ value for AMIR $=1.98-4$

Mean K value for steel roller $=2.02-3$

Ratio of the $\mathrm{K}$ values of Steel roller and AMIR $=10.2$

Table 7. Permeability Test Results Tomlinson Power Rd Yard, 2012

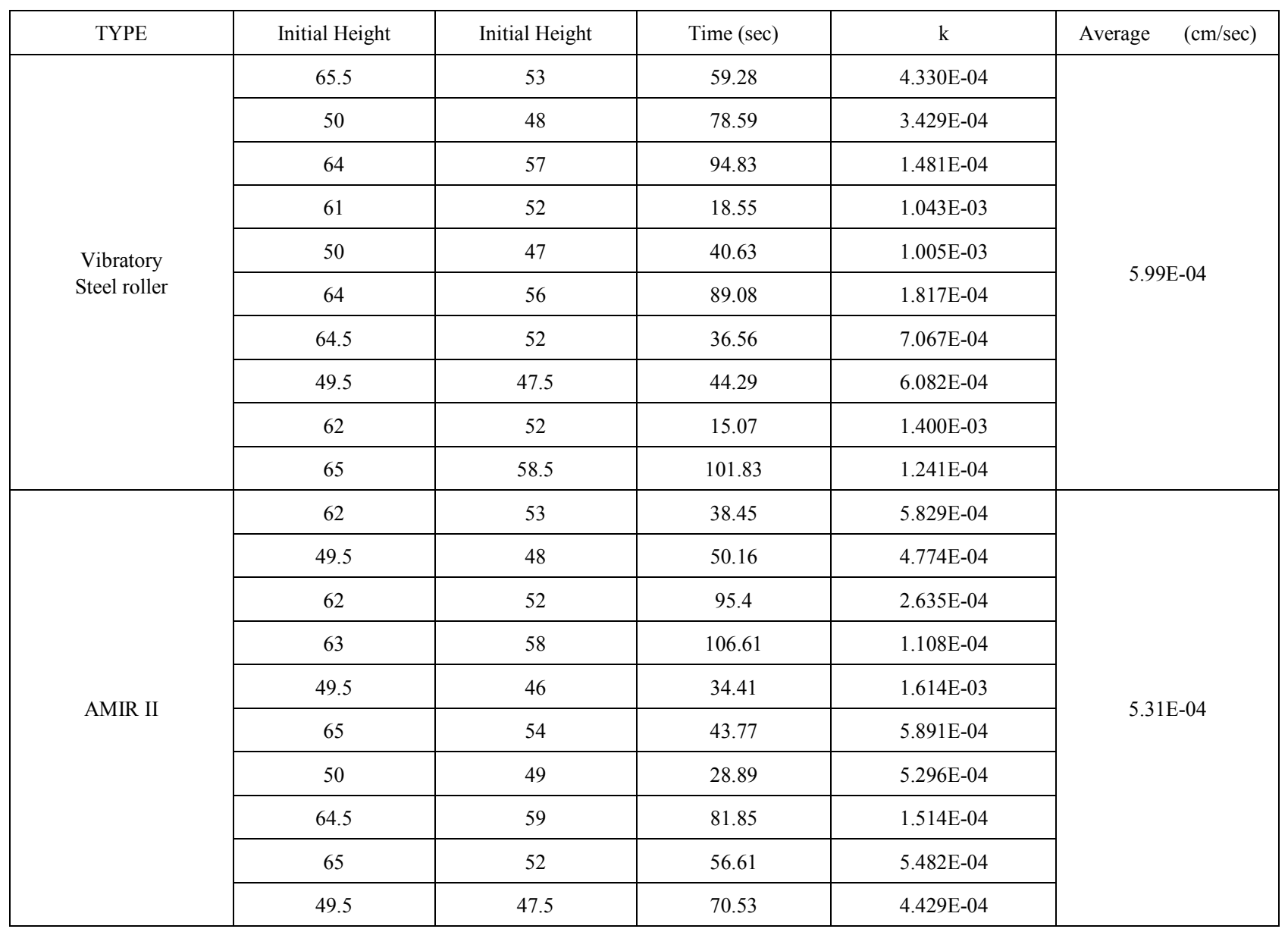

Mean $\mathrm{K}$ value for AMIR = 5.31-4

Mean K value for steel roller $=5.99-4$

Ratio of the $\mathrm{K}$ values of Steel roller and AMIR $=1.1$ 
Location: Tomlinson Power Rd Yard, 2012

Table 8. BRD and Tensile strength (direction of rolling)

\begin{tabular}{|c|c|c|c|}
\hline \multicolumn{2}{|c|}{ BRD } & \multicolumn{2}{c|}{$\begin{array}{c}\text { Tensile strength } \\
\text { (direction of rolling) KN/m2 }\end{array}$} \\
\hline AMIR & Vibratory Roller & AMIR & 147.31 \\
\hline 2.423 & 2.354 & 235.97 & 127.74 \\
\hline 2.463 & 2.354 & 312.95 & 173.76 \\
\hline 2.386 & 2.355 & 186.96 & 141.50 \\
\hline 2.389 & 2.307 & 188.62 & 166.75 \\
\hline 2.363 & 2.313 & 278.53 & \multicolumn{2}{c|}{} \\
\hline
\end{tabular}

Table 9. BRD and Tensile strength (perpendicular to rolling Direction)

\begin{tabular}{|c|c|c|c|}
\hline \multicolumn{2}{|c|}{ BRD } & \multicolumn{2}{c|}{$\begin{array}{c}\text { Tensile strength } \\
\text { (perpendicular to rolling) KN/m2 }\end{array}$} \\
\hline AMIR & Vibratory Roller & AMIR & 146.29 \\
\hline 2.385 & 2.320 & 213.86 & 219.67 \\
\hline 2.332 & 2.369 & 241.18 & 119.10 \\
\hline 2.465 & 2.374 & 252.54 & 164.08 \\
\hline 2.357 & 2.282 & 169.66 & 81.55 \\
\hline
\end{tabular}

Mean AMIR BRD $=2.408$

Mean Vibratory Steel Roller $=2.342$

Mean AMIR Tensile strength $=232.00$

Mean Vibratory Steel Roller tensile strength $=148.7$

\subsection{Durability of HMA compacted using AMIR II}

In a previous study [17] performed using AMIR I in 1991, flexural tests were performed on beams recovered from a 70 mm HL4 asphalt overlay of 2 field test sections side by side, one section compacted using AMIR I while the other compacted using the conventional 3-roller method. The bending testes were carried out under 4 different temperatures: $18^{\circ} \mathrm{C}, 0^{\circ} \mathrm{C},-20^{\circ} \mathrm{C}$, and $-40^{\circ} \mathrm{C}$. Table 9 provides summary of the flexural test results.

Table 9. Summary of the flexural test results

\begin{tabular}{|c|c|c|c|}
\hline \multirow{2}{*}{$\begin{array}{c}\text { Temperature } \\
(\mathrm{oC})\end{array}$} & \multicolumn{2}{|c|}{ Stress (MPa) } & $\begin{array}{c}\text { Ratio } \\
(\%)\end{array}$ \\
\cline { 2 - 4 } & AMIR & Vibratory/Pneumatic & A/V.P \\
\hline 18 & 1.34 & 0.87 & 154 \\
\hline 0 & 5.09 & 4.58 & 111 \\
\hline-20 & 4.99 & 4.75 & 109 \\
\hline-40 & 4.09 & 3.34 & 122 \\
\hline
\end{tabular}

The results shown in the table suggest that the AMIR compacted method will produce asphalt pavement qualities that are superior to those obtained by current compaction equipment. Furthermore, as shown in Table 9 the flexural strength of the AMIR compacted sections is higher over a range of temperature between $18^{\circ} \mathrm{C}$ to as low as $-40^{\circ} \mathrm{C}$, ranging from $109 \%$ to $145 \%$ and an overall average ratio of $115 \%$ over the entire range of the temperature. The lower permeability, crack-free texture, higher densities, better indirect tensile strength and higher flexural strength over wide range of temperatures will certainly result in longer life of the AMIR compacted pavement with less maintenance and rehabilitation costs. The lower permeability and crack free surface will contribute to prevention of development of potholes and stripping distress of the asphalt layer. Higher flexural strength over wide range in temperatures will certainly have higher resistance to thermal induced cracks. These advantages are achieved with less number of compaction equipment which also will require less labour, energy and time on the job.

\section{Conclusion}

The development of an innovative approach termed the Asphalt Multi Integrated Roller (AMIR) was tested on Ministry of Transportation Ontario highways and it has shown the advantages of producing tighter, smoother, less permeable and cost effective surface than the current HMA conventional compaction method is shown in this research (1st conclusion). 
As asphalt pavement makes $95 \%$ of the highway network in Ontario, without any significant improvement in asphalt compaction long term performance of pavement is unlikely to be achieved. This is demonstrated from the research carried out over the past two decades in the field of asphalt compaction (2nd conclusion).

The advantages of Asphalt Multi-Integrated Roller method are presented in this paper as well as in several other publications. This paper aimed at assessing the relationship between current HMA compaction techniques and AMIR II. The results of two different test sections using two different types of Ontario hot laid asphalt mixes compacted by AMIR and current compaction techniques showed significant improvement in the mechanical and physical properties of the finished pavement with crack free asphalt surface (3rd conclusion).

The test results from this study are in general agreement with the previous AMIR studies (4th conclusion).

It is expected that when AMIR technology is fully developed asphalt pavements will be constructed and built to last as designed. Thus saving the initial capital investment and reducing maintenance and rehabilitation costs.

\section{Acknowledgements}

The authors wish to acknowledge the cooperation of R.W.Tomlinson Limited for their appropriate and constructive suggestions for AMIR II and very grateful to Ministry of Transportation Eastern Region, NSERC and Carleton University for their financial support and cooperation.

\section{REFERENCES}

[1] Ontario Hot Mix Producers Association- Asphalt Fact Sheet $-2012$

[2] Ontario's Transportation Technology Transfer Digest spring 2010 - Vol. 16, Issue 2

[3] Ontario Provincial Standard Specifications-2012

[4] Geller, M. (1982) "Compaction Equipment for Asphalt Mixtures". Placement and Compaction of Asphalt Mixtures, ASTM STP 829, American Society for Testing and Materials, Philadelphia, PA. p. 28.

[5] Abd El Halim Omar Abd El Halim and Abdelzaher Mostafa (2006) "Asphalt Multi-Integrated Rollers and Steel Drum Compactors Evaluating Effect of Compaction on
Permeability of Asphalt Pavements". Journal of Transportation Research Board, No. 1967, 2006, pp. 173-180

[6] Abd El Halim, A.O., Haas, R. and Svec, O.J. (1994) "Improved Asphalt Pavement Performance Through a New Method of Compaction". Proc., 17th ARRB Conference, Part. 3. pp. 175-191.

[7] Abd El Halim, A.O., Phang, W. and Haas, R.C. (1993) "Unwanted Legacy of Asphalt Pavement Compaction". Journal of Transportation Engineering, Vol. 119, No. 6, November/December. pp. 914-932.

[8] Brown, D. (1998) "Solving Compaction Problems with Superpave Mixes". Engineering News Record, March 23rd, pp. T21-T27.

[9] Himeno K, Watnabe T (1987). "Design of Asphalt Pavements", Proc., Six International Conference on Structural Design of Asphalt Pavements, Ann-Arbour, Michigan.

[10] Christison TJ (1972). "The Response of Asphalt Concrete Pavements to Low Temperature", Ph.D. Dissertation in Civil Engineering, University of Alberta, Canada.

[11] Abd El Halim, A.O. and Bauer, G.E. (1986) "Premature Failure of Asphalt Overlays at Time of Construction". Journal of Transportation Forum, Road and Transportation Association of Canada, Vol. 3.2. Sept., 1986, pp. 52 to 58

[12] Abd El Halim, A.O., Phang, W. and Haas, R.C. (1987). "Realizing Structural Design Objectives Through Minimizing Of Construction Induced Cracking”, Proc., Sixth International Conference on Structural Design of Asphalt Pavements, Ann Arbor, U.S.A., July 13-16, Vol. I., pp.965-970.

[13] Grootenboer, H.J., "Compaction of Asphalt Road Pavements", H.L. ter Huerne, Enschede, the Netherlands, 319 pp., 2004

[14] Abd El Halim, A.O., Phang, W., and El Gindy, M. (1988). "Extending the Service Life of Asphalt Pavements Through the Prevention of Construction Cracks". Transportation Research Record No. 1178, 1-8.

[15] Abd El Halim, A.O., and R. Haas, (2004). "Process and Case Illustration of Construction Innovation: From Concept to Commercial Realization", Journal of ASCE Construction Engineering and Management, Volume 130, Issue 4, pp. 570-575.

[16] Rickards I, Goodman S, Pagai J, Abd El Halim AO, Haas R (1999). "Practical Realization of a New Concept for Asphalt Compaction" Transportation Research Record No. 1654, pp. 27-35.

[17] Svec, O. J.; El Halim, A. O., "Field verification of a new asphalt compactor, AMIR ", Canadian Journal of Civil Engineering, 18, 3, pp. 465-471, 1991 